\title{
Utilização do design participativo na definição de um processo colaborativo para a elaboração de instrumentos legais participativos
}

\author{
Jonas Henrique Ribeiro Paula e Melise Maria Veiga de Paula \\ Programa de Pós-Graduação em Ciência e Tecnologia da Computação \\ Universidade Federal de Itajubá (UNIFEI) - Itajubá - MG - Brasil \\ jonashenrq@gmail.com, melise@unifei.edu.br
}

\begin{abstract}
The City Statute is a Brazilian federal law that regulates urban policy across the country through legal instruments designed to organize the growth of cities that must be developed in a participatory manner. To meet this objective, this article proposes the use of Participatory Design in the elaboration of these instruments using information and communication technology to expand the opportunities for collaboration between the members involved in this process.
\end{abstract}

Resumo. O Estatuto da Cidade é uma lei federal brasileira que regulamenta a política urbana em todo o país através de instrumentos legais elaborados para organizar o crescimento das cidades que devem ser desenvolvidos de forma participativa. Visando atender este objetivo, este artigo propõe a utilização do Design Participativo na elaboração destes instrumentos usando a tecnologia de informação e comunicação como meio para ampliar as oportunidades de colaboração entre os membros envolvidos neste processo.

\section{Introdução}

O Estatuto das Cidades (EC) regulamenta os artigos 182 e 183 da Constituição Federal, estabelecendo um conjunto de instrumentos que combinados determinam como deve ser feita a política urbana em todo o país. Estes instrumentos estabelecem normas de ordem pública e interesse social para regular o uso da propriedade urbana em prol do bem coletivo, da segurança e do bem-estar dos cidadãos, assim como o equilíbrio ambiental [BRASIL 2001]. Um destes instrumentos, por exemplo, é o Plano Diretor Participativo que determina como o poder público municipal e a iniciativa privada devem atuar na oferta dos serviços públicos essenciais e determina normas para a construção nos espaços urbano e rural.

A elaboração destes instrumentos envolve a colaboração de pessoas de diversas áreas do conhecimento, diferentes departamentos da gestão pública municipal e a sociedade civil com o objetivo de identificar quais são as demandas da cidade e da população sob diferentes perspectivas [Pinheiro 2014]. Porém, os envolvidos podem ter agendas conflitantes e demandas divergentes sobre as escolhas públicas, sendo necessário um espaço colaborativo para que possam apresentar seus pontos de vista de forma a assegurar a equidade do conteúdo dos instrumentos [Weise et al. 2017]. Além disso, os envolvidos podem não se engajar nesses espaços colaborativos, criando a 
necessidade de também identificar formas de mantê-los motivados em colaborar nesses ambientes.

Diante disto, este trabalho faz parte de uma pesquisa em andamento que visa mitigar este problema através da criação um modelo de processo que utiliza a tecnologia de informação e comunicação como intervenção para apoiar a colaboração dos atores envolvidos no processo, sob a perspectiva da colaboração e do engajamento. Para a concepção dos artefatos do processo colaborativo está sendo utilizado o Design Participativo (DP).

Esta pesquisa está sendo desenvolvida em parceria com o Núcleo Estratégico Interdisciplinar de Resiliência Urbana (NEIRU) que é um núcleo de pesquisa e extensão vinculado a Universidade Federal de Itajubá. O NEIRU auxilia os municípios na elaboração e revisão dos instrumentos legais do EC. A proposta é usar o DP nos projetos executados pelo NEIRU com o objetivo de propor artefatos que ampliem os espaços de colaboração dos responsáveis pela elaboração dos instrumentos do EC. Nesse artigo será descrita a abordagem proposta.

\section{Trabalhos Relacionados}

Nessa seção serão descritos trabalhos nos quais o objetivo foi utilizar o design participativo em algum contexto que envolve a gestão pública e a utilização de soluções colaborativas. A princípio, o DP pode ser utilizado em diferentes contextos, incluindo a gestão pública, como observado em Camargo e Fazani (2014). Nesse artigo, os autores fizeram um levantamento das ferramentas que utilizaram o DP em sua concepção e desenvolvimento, como resultado, identificaram que o DP foi utilizado no tratamento de questões sobre democracia e participação dos usuários. Segundo os autores, nos resultados dos trabalhos levantados, foram observados uma maior aceitação, maior usabilidade e acessibilidade do sistema.

Boella et al. (2019) apresentam uma rede social cívica chamada FirstLife, que combina informação geográfica voluntária com funcionalidades de redes sociais. Baseados em informações geográficas de crowdsourcing os autores propõem uma estrutura digital para apoiar a coordenação, cooperação e colaboração entre os cidadãos e instituições públicas. $O$ artigo descreve que o desenvolvimento adotou uma abordagem de design centrada no usuário por meio de ciclos de design participativo que evoluíram continuamente a plataforma.

O processo apresentado em Boella et al. (2019), pode ser dividido em duas fases principais: a fase de laboratório e a fase de workshop. A fase de laboratório foi organizada para permitir que aqueles que participam efetivamente da vida urbana da cidade cooperassem para encontrar oportunidades e desafios para o desenvolvimento da plataforma. Já os workshops tinham o objetivo de manter o engajamento das partes interessadas a fim de refinar os requisitos e validar o modelo. O modelo da plataforma resultou em uma representação de entidades complexas espelhando a dinâmica do mundo real e permitindo a colaboração das partes interessadas.

Araujo et al. (2014) apresentaram o uso do DP na elaboração de um sistema de gestão pública de saúde, denominado PRONTO, com o objetivo de ser um prontuário eletrônico para atendimentos multidisciplinares do sistema público de saúde. O projeto envolveu uma rede de saúde com 64 unidades de saúde da família, 8 ambulatórios e 1 policlínica da cidade de Blumenau/SC. O desenvolvimento foi através da prototipagem 
do sistema com o envolvimento das equipes de profissionais de saúde do município com as equipes de desenvolvimento através de encontros semanais.

Os protótipos criados em Araujo et al. (2014) foram validados com os stakeholders do município. De acordo com os autores, os usuários se sentiram mais confiantes em usar o sistema por ter participado do desenvolvimento. No aspecto de sistemas colaborativos, segundo os autores, esta técnica foi muito importante pois o auxílio de uma equipe colaborativa com o uso do DP foi possível identificar funcionalidades importantes.

\section{Design da elaboração dos instrumentos legais}

Esta pesquisa está seguindo os três estágios básicos do design participativo apresentada por Spinuzzi (2005), os estágios são: exploração inicial do trabalho, processo de descoberta e prototipagem. Na etapa de exploração inicial, os designers encontram os usuários e se familiarizam com as formas como os usuários trabalham juntos. No processo de descoberta, designers e usuários empregam várias técnicas para entender e priorizar a organização do trabalho e prever o futuro local de trabalho. Já na prototipagem, designers e usuários modelam artefatos tecnológicos de forma iterativa para satisfazer o que foi previsto no estágio de descoberta. Os estágios podem ser (e geralmente devem ser) iterados várias vezes.

Para o estágio inicial, serão mapeados os subprocesso realizados e a análise dos subprodutos gerados em cada instrumento, com o objetivo de entender o procedimento de trabalho, rotinas e atores envolvidos. No estágio de descoberta, serão realizadas entrevistas semiestruturadas com os atores chaves de cada processo identificados no estágio inicial. Já no estágio de prototipagem, será proposto um protótipo com artefatos que ampliem os espaços de colaboração, de acordo com as necessidades identificadas no estágio anterior, as funcionalidades deste protótipo serão validadas com os membros envolvidos na elaboração e revisão dos instrumentos.

No estágio inicial, foram analisados diferentes documentos relacionados à elaboração ou revisão dos instrumentos do EC. Os processos executados pelo NEIRU, envolvem diversos tipos de atores, cada um com atribuições especificas, como os cidadãos, influenciadores da cidade, grupo de trabalho executivo, núcleo gestor e a equipe executora, ambos foram descritos em Paula, Caetano e Paula (2021). Nesta pesquisa estão sendo considerados os seguintes atores: Equipe Executora (EE): composta por técnicos (podendo ser terceirizados) que devem dar orientações e conduzir as atividades do processo de elaboração ou revisão dos instrumentos legais. São esses atores que elaboram de fato o plano. Núcleo Gestor (NG): é um grupo de pessoas responsável por assessorar e fornecer informações para a equipe executora e assegurar a comunicação com o poder executivo e os atores da sociedade civil, podendo ser considerados os representantes da população. O NG deve ser, obrigatoriamente, representativo, ou seja, os diversos segmentos da sociedade e lideranças do município devem ser representados por exemplo, associações de bairro, associações comerciais, empresas, ONGs, movimentos sociais, sindicatos rurais e/ou comercias, dentre outros. Grupo Trabalho Executivo (GTE): é um grupo composto por representantes da gestão pública municipal. Suas contribuições consistem basicamente em assegurar que a elaboração do plano esteja de acordo com os fins definidos pelo contrato estabelecido, caso o instrumento esteja sendo realizado de forma terceirizada. 
Os projetos de elaboração dos instrumentos executados pelo NEIRU estão baseados em quatro fases: planejamento, elaboração, propostas e consolidação. Na fase de planejamento é definido como o projeto será executado, os atores envolvidos e o cronograma. $\mathrm{Na}$ fase de elaboração são realizados os diagnósticos participativos e técnicos sobre os principais problemas encontrados no município pela população, além dos pontos fortes e fracos da cidade. Após a fase de elaboração são definidos um conjunto de propostas que prioriza as melhores alternativas para solução dos problemas identificados. Já na fase de consolidação é elaborada uma minuta de lei e definido mecanismos para acompanhar a execução do plano. Todas as fases possuem subprodutos que definem detalhadamente as estratégias. Além disso, em todas as fases são executadas algumas oficinas estratégicas e seminários com o objetivo de mobilizar e informar os atores envolvidos no plano e a população. Com o advento da pandemia de COVID-19, todos os processos estão sendo realizadas de forma on-line.

Um dos subprodutos elaborados na fase de planejamento é o Plano de Comunicação e Participação Social que define toda a estratégia de mobilização social e comunicação na elaboração dos instrumentos. Essa estratégia foi o primeiro subprocesso analisado detalhadamente no estágio inicial nesse trabalho e o resultado foi publicado em Paula, Caetano e Paula (2021). Após a análise observou-se que os membros da Equipe Executora são os responsáveis por comandar o fluxo das atividades da elaboração dos instrumentos e que o núcleo gestor tem um papel importante, dado sua representatividade no processo.

Nessa iteração do DP, passando para o estágio de descoberta, foi realizada uma entrevista semiestruturada com os gerentes da equipe executora do NEIRU, com o objetivo de analisar como é a relação da EE com o NG, focando nas dificuldades e potencialidades de comunicação, coordenação, cooperação e engajamento de ambas as partes. Atualmente no NEIRU, existem dois projetos sendo realizados. Em cada um, a equipe é gerenciada por um membro sênior que coordena os demais membros executores. Vale destacar que as equipes são coordenadas por um professor da Universidade Federal de Itajubá. Como o interesse nesse estágio do trabalho foi conhecer melhor o aspecto operacional do projeto, os dois membros seniores das equipes foram entrevistados.

Nas entrevistas, foi relatada a falta de engajamento no processo por parte dos membros do NG. Como forma de evidenciar isso qualitativamente, foi informado que menos da metade dos membros do núcleo estão participando das oficinas. Também disponibilizados formulários para a coleta de alguma informação e, assim como no caso anterior, poucas pessoas responderam. Além disso, os membros que respondem os formulários, ao saber da resposta e justificativa dos outros membros trocaram de opinião, sendo necessária uma nova discussão na reunião presencial.

Outra constatação relatada pelo entrevistado se refere aos recursos que antes eram utilizados nas oficinas presenciais. Alguns desses são difíceis de serem adaptados às dinâmicas das oficinas on-line. Como exemplo, foi citado um mapa que antes era apresentado aos participantes para que eles pudessem apontar regiões da cidade que representavam uma ameaça ou uma oportunidade ao desenvolvimento da cidade. Ao tentar realizar essa dinâmica de forma virtual, os membros da EE tiveram vários impedimentos. 
Ao fim da entrevista foi aberto um espaço para sugestões e um diálogo livre com o pesquisador, os entrevistados sugeriram a criação de um fórum para que os membros saibam da opinião do colega nas atividades que não necessitam de reunião presencial. Um dos entrevistados alertou que, entre os membros do NG, podem existir pessoas que não têm acesso à um computador ou possui acesso, mas não tem um smartphone, sendo necessário que os artefatos tecnológicos sejam responsivos.

\section{Considerações Finais}

Com as entrevistas com a EE foi possível confirmar que existe uma falta de participação e engajamento por parte do NG. Com base nas sugestões dos entrevistados, existe a possibilidade de a intervenção da tecnologia ser um meio para mitigar alguns dos problemas relatados. Em relação às oficinas, pode-se pensar em formas de utilizar a tecnologia para que elas ocorram de maneira eficaz de forma on-line.

Como cada membro possui características distintas, serão realizadas novas iterações do DP com os membros do GTE e NG, em momentos separados, com o objetivo de entender as especificidades, dificuldades e potencialidades de colaboração e formas de aumentar o engajamento sob suas perspectivas, já levando em consideração os dados levantados com a EE. Com o uso do DP na elaboração do processo colaborativo e na definição dos artefatos, espera-se que esta pesquisa resulte em um ambiente eficaz de colaboração para que os membros participem efetivamente no processo, de forma democrática, e que os membros se sintam motivados a participar.

\section{References}

Araujo, L. P., Berkenbrock, C. D. M., Mattos, M. M. and Boeing, E. (2014). Using participatory design in designing phase of collaborative systems. In Proceedings of the 2014 IEEE 18th International Conference on Computer Supported Cooperative Work in Design (CSCWD).

Boella, G., Calafiore, A., Grassi, E., et al. (2019). FirstLife: Combining Social Networking and VGI to Create an Urban Coordination and Collaboration Platform. IEEE Access, v. 7, p. 63230-63246.

BRASIL (2001). Lei No 10.257, de 10 de jul. 2001. 11 jul 2001.

Camargo, L. S. de A. and Fazani, A. J. (2014). Explorando o Design Participativo como Prática de Desenvolvimento de Sistemas de Informação. InCID: Revista de Ciência da Informação e Documentação, v. 5, n. 1, p. 138.

Paula, J. H. R., Caetano, B. P. e Paula, M. M. V. (2021). Utilização de um modelo de engajamento colaborativo na elaboração de instrumentos legais participativos. In Anais do XVI Simpósio Brasileiro de Sistemas Colaborativos (SBSC).

Pinheiro, O. M. (2014). Plano diretor e gestão urbana. 3. ed. Florianópolis: CAPES : UAB.

Spinuzzi, C. (2005). The methodology of participatory design. Technical communication, v. 52, n. 2, p. 163-174.

Weise, S., Coulton, P. and Chiasson, M. (2017). Designing in between Local Government and the Public - Using Institutional Analysis in Interventions on Civic Infrastructures. Computer Supported Cooperative Work (CSCW), v. 26, n. 4-6, p. 927-958. 